\title{
LAS “NARRATIVAS” DESDE LA HIPERTEXTUALIDAD. CARACTERÍSTICAS, MODELO Y METODOLOGÍA A PARTIR DE LA INTELIGENCIA SINTIENTE
}

\author{
Olga Lucía Londoño Palacio, Ph.D. ${ }^{12}$ \\ Tiempo, sueño y memoria pueden fundirse \\ $y$, el deber del lector es perderse \\ en el torbellino de su indistinción. \\ Umberto Eco
}

\begin{abstract}
RESUMEN
En este artículo se presenta una visión en torno a los nuevos escenarios en los que surgen las actuales narrativas digitales, que obligan a repensar los desafíos y retos para afrontar el presente siglo, caracterizado entre otros aspectos, por algunos rasgos de la Postmodernidad. Las narrativas anteriores a la Posmodernidad muestran la realidad como un estado común y dan una respuesta panorámica a los problemas humanos. Por ello, en especial las Ciencias Sociales y Humanas reconocen nuevas formas de acercamiento al hacer y al sentir humanos, desde la cercanía que permite el estudio de lo Cotidiano. Al intentar crear crear una estructura musical, después de un preludio narrado desde la Inteligencia Sintiente (obertura), surge el primer movimiento, cuyo objetivo es caracterizar a las narrativas digitales, como una nueva manera de contar. Se pasa luego al segundo movimiento, donde se plantea el papel que desempeñan los investigadoresautores que trabajan desde esta forma narrativa. El tercer movimiento se centra en el Sistema de Marcos, como formato ideal para la creación de hipertextos. El transcurrir metodológico de un hipertexto ideado desde el Sistema de Marcos es la línea melódica para el cuarto movimiento. En el consabido finale, se retoma lo anterior para cerrar rítmicamente la pieza musical a través de una serie de conclusiones y recomendaciones.
\end{abstract}

Palabras clave: narrativa, metanarrativa, Modernismo, Posmodernismo, inteligencia sintiente, inteligencia artificial.

\begin{abstract}
This article presents a view to characterize the new scenarios in which the new digital narratives emerge; obliged to rethink the challenges to face the present century, characterized by some features of the postmodernity. In such narratives, virtual reality is a state that is developed in common places, and gives a global response to human problems. For that reason, and especially from the Social and Human Sciences point of view, new forms of proximity

12 Licenciada en Filosofía y Humanismo (Universidad Santo Tomás de Bogotá). Especialista en Investigación Lingüística y Literaria (OFINES, Madrid). Especialista en Filología Española (Universidad de Málaga - España). Magister en Hábitat (Universidad Nacional de Colombia). Doctora en Filosofía, con énfasis en Antropología (Atlantic International University, La Florida - USA). Actualmente forma parte del equipo que está estructurando el Doctorado en Gestión del Conocimiento en la Universidad Nacional Abierta y a Distancia - UNAD.
\end{abstract}


are recognized among different ways of doings and feelings, telling of different people and cultures, from nearness that allows daily life study. Trying to create a musical structure after a prelude narrated since Sentient Intelligence (overture), appear a first movement, whose target is to characterize digital narratives as a new way for telling a story. Then, begin the second movement showing the role of the researcher-authors working about a narrative form. The third movement focuses on the frame-system as an ideal format for the creation of hypertext. The methodological passing in a hypertext devised from the frame-system, is the melodic line for the fourth movement. The usual finale, rhythmically closet he musical part of a series of conclusions recommendations.

Key words: narrative, meta-narrative, Modernism, Postmodernism, Sentient Intelligence, Artificial Intelligence.

Recibido: 6 de noviembre de 2009 Aceptado: 2 de marzo de 2010

\section{INTRODUCCIÓN}

El término narrativa, además de referirse al milenario género literario, alude también a otras formas que utilizan diversos lenguajes con el fin de contar hechos, historias, situaciones o acontecimientos que pueden estar ubicados en el pasado, el presente o el futuro y en un lugar o lugares determinados. Hoy se habla de narrativas digitales y de metarrelatos, acompañados de las denominadas tecnologías digitales de la información y la comunicación, de los que se espera cambien, de una manera profunda, las funciones que la manera de relatar tradicional acostumbra perpetrar.

La tecnología ha abierto la posibilidad de crear y representar la realidad desde narrativas que se ensanchan en forma de imágenes, sonidos y palabras. Más específicamente, la informática está promoviendo la formalización innovadora y creadora de modelos y técnicas narrativos, que desde la Inteligencia Sintiente permiten el diseño de nuevas estrategias discursivas que confieren curiosos niveles de complicidad lectora como pacto de verosimilitud con los relatos digitales.

Es importante resaltar que la narrativa hipertextual, como cualquier texto narrativo es una apuesta a la fidelidad de una enorme multitud de voces que cuentan simultáneamente relatos sobre hechos, acontecimientos, situaciones, sueños y sugerencias, para ser recontados desde una estructura abierta y flexible. Bien podría decirse que es como un experimento mental guiado por la Inteligencia Sintiente, que utiliza diversos lenguajes, donde el papel dialéctico y dialógico del lector y del autor, está circunscrito por las mismas estructuras narrativas.

La manera como está organizado el presente artículo, explicación histórica, obertura, cuatro movimientos y un finale, significa que el texto aquí presentado adquiere la forma de una estructura musical, para ser leído y disfrutado por sí mismo y desde sí mismo, con una inmensa solemnidad y una necesaria empatía con el silencio, evitando así distraer la concentración del paciente lector. Como en toda obra musical clásica lo que se desea es comunicar una 
emoción en torno a la manera de contar narrando, una de las expresiones más maravillosas que identifican al ser humano.

\section{PLANTEAMIENTO DEL PROBLEMA}

Con el paso de la Modernidad a la Posmodernidad, se plantea que el ser humano contemporáneo está viviendo la época del fin de los grandes relatos, justificada por el pensamiento que da lugar al Posmodernismo y por el pluralismo en el que habitan las sociedades contemporáneas, surgidas debido al fracaso experimentado por las grandes palabras que movilizaron a los hombres de la Modernidad occidental en aras de la verdad, la libertad, la justicia y la racionalidad. (Alpini: s/f).

El anterior proceso dio origen a nuevos sujetos históricos, quienes semánticamente desencantados por la fragilidad conceptual, resolvieron encontrar su identidad en agrupaciones reducidas, logrando con ello obtener una visión fragmentada de la realidad posible de ser plasmada en narrativas; a su vez, el resultado obtenido de la suma de fracciones es una mirada totalizadora de la realidad, que si se organiza y representa en forma de hipertexto, faculta ser apreciada como una cadena de realidades, que en últimas, es de la que realmente está compuesta por la realidad de las realidades humanas.

En consecuencia, se hace necesaria la reflexión y la acción narrativa para hacer de la labor investigativa una experiencia de vida centrada en el otro y en la construcción de saberes que contribuyan a seguir siendo ciudadanos del mundo, en un concierto que buscando la armonía de lo global no permita que se pierda el sentido y el significado de lo local.

De acuerdo con lo anterior, las preguntas que orientan el presente trabajo son:

- ¿De dónde surge la idea de elaborar narrativas hipertextuales?

- ¿Cuál es la pragmática del saber hipertextual desde la Inteligencia Sintiente?

- ¿Cuáles son las características de las narrativas hipertextuales?

- ¿Qué papel desempeña el autor de hipertextos desde el ámbito investigativo?

- ¿Qué relación establecen un autor y un lector de hipertextos?

- ¿Qué modelo y metodología son pertinentes para la construcción de hipertextos?

\section{OBJETIVOS}

\section{Objetivo general}

Definir las características, modelos y metodología de la Narrativa hipertextual desde el reconocimiento de su evolución histórica y algunas propuestas teóricas relacionadas con este concepto, a partir de algunos principios proporcionados por la Inteligencia Sintiente. 


\section{Objetivos específicos}

- Rastrear los antecedentes y la evolución de los términos relato y metarrelato, con el fin de comprender las distintas estructuras y estéticas con las que se formaliza la Narrativa Hipertextual.

- Proponer, con base en una ontología pertinente, criterios para una caracterización de las estructuras narrativas hipertextuales, desde la Inteligencia Sintiente.

- Examinar las relaciones entre el escritor y el lector cuando entran en contacto con la narrativa hipertextual.

- Visualizar las problemáticas en torno a las exigencias creativas del hipertexto, dado su carácter híbrido (síntesis de arte, ciencia y tecnología, de palabras, sonidos e imágenes).

- Proponer un modelo y una metodología para la construcción de hipertextos narrativos.

\section{JUSTIFICACIÓN}

Una forma natural de la comunicación entre los seres humanos es la narración, pues es costumbre contar lo que se hace, lo que sucede a nuestro alrededor, lo que se desea, se sueña, se odia, se teme o se sabe. También suele decirse que la narración es un género capital que envuelve a otros: siempre hay una historia detrás de todo relato, así como siempre hay un relato detrás de toda historia. Por lo general, al pensar en los términos narrativa, relato o metarrelato, las imágenes se remontan a la crítica literaria o a la narratología, disciplinas cuyo objeto de estudio es el texto de ficción literaria, sin contemplar que la amplitud semántica de dichos términos, permite remontarse a otros saberes y dimensiones. Por esta razón, se considera relevante precisar y ampliar sus límites conceptuales, sus características, modelos y métodos.

El hipertexto, entendido sólo como una facilidad para crear nodos y establecer enlaces, está mucho más cerca del ideal tecnológico. Por ello, es necesario concebirlo desde una posición epistemológica, para que empiece a actuar análogamente, sirviendo como mediador de las expresiones humanas y de las representaciones sociales. Hoy no es suficiente saber e informarse acerca de realidades que, simplemente, están ahí; es necesario que el lugar físico de la realidad se disuelva en favor de la cooperación y la comunicación, estableciendo vínculos entre los lugares, las problemáticas y los lenguajes. Visto de esta forma, es posible entender al hipertexto como el modo de expresión de la nueva situación epistemológica y de sus pragmáticas, esto es, un modelo que sin desconocer las particularidades pueda ser totalizante, permitiendo con ello una comunicabilidad infinita, cargada de posibilidades expresivas y de nuevas formas de acercamiento conducentes a gestionar el conocimiento.

Para no permitir que las narrativas se conviertan en una especie de a priori sin el cual nada es comprensible, la Inteligencia Sintiente actúa como carta de navegación del hipertexto. Las múltiples representaciones a las que apuntan las diferentes formas que pueden adoptar las narrativas digitales, permiten reconocer las distintas realidades de una misma realidad, entendiendo que el hipertexto conformado por narrativas es un espacio viable para fundamentar el ser y el existir de las obras humanas vividas, ya que son éstas las que tienen 
sentido y posibilidad de ser narradas, mientras se ajusten a las acciones a partir de las cuales se fabrica el medio en el que esa realidad es o quiere ser.

\section{CONTEXTUALIZACIÓN HISTÓRICA}

En el ámbito literario el término relato se utilizó ampliamente en la corriente estructuralista francesa, ${ }^{13}$ reconocida como la fuente de la teoría de la narración o narratología, concretamente en las obras de Barthes y Genette y se define como un texto en forma narrativa que se ubica, por razones de extensión, entre la novela y el cuento. En su obra Análisis Estructural del Relato, Barthes (1966: 12, 14), refiriéndose a esta forma narrativa literaria, afirma que comprenderla (...) no es sólo seguir el desentrañarse de la historia, es también reconocer estadios, proyectar los encadenamientos horizontales del hilo narrativo sobre un eje implícitamente vertical; leer (escuchar) un relato, no es sólo pasar de una palabra a otra, es también pasar de un nivel a otro.

En coincidencia con Barthes, Genette (2002) explica que el término relato se debe enmarcar dentro del contexto de la ficción literaria. Dicho autor asegura que historia y narración sólo existen si están mediados por el relato. Pero, recíprocamente, el relato o discurso narrativo no existe sino en la medida en que cuente y divulgue una historia. De ahí que para Genette, el análisis del discurso narrativo o relato, sea en esencia el estudio de las relaciones entre relato e historia, entre relato y narración y, en la medida en que se inscriben en el discurso del relato, entre historia y narración. Todo relato, dice, es un enunciado narrativo, representado por un discurso oral o escrito que entraña la relación de un acontecimiento o de una serie de acontecimientos.

A pesar de las definiciones dadas por los dos autores franceses, quienes admiten una filiación literaria del término relato, es necesario aclarar que, éste es comúnmente utilizado de manera plurivalente al relacionárselo con la forma narrativa; es decir, perteneciente a cualquier subgénero que utilice la narración. Por ello, además de hablarse del relato literario, se hace referencia igualmente al relato periodístico y al cinematográfico. En palabras de Maestro (1984):

Convencionalmente se admite el uso del término relato para designar un conjunto de obras cuyo discurso es fundamentalmente narrativo (novela, cuento, filme, comic...) La narratividad es una propiedad discursiva que, surgida originariamente en formas épicas, se sistematiza literariamente en la novela con la llegada de la Modernidad; la narratividad puede manifestarse en sistemas sémicos muy diversos, en manifestaciones artísticas pertenecientes a géneros muy distintos entre sí.

Durante las últimas décadas del siglo xx surge el Postmodernismo, afirmando que no cree en fundamentos universales sino en relaciones que se basan en otras relaciones, que a su vez conducen a nuevas relaciones y van conformando cadenas de significantes, sentidos y significados que permitan narrar narrativas, describir descripciones y observar observaciones.

13 El estructuralismo es un enfoque de las ciencias humanas y sociales que surgió en la segunda mitad del siglo xx, con el objetivo de proponer un modelo para explorar las interrelaciones estructurales que producen significados dentro de una cultura. Como origen, se reconoce la obra del lingüista Ferdinand de Saussure. 
Por esto, es un momento que decreta la muerte de las ideologías y de las interpretaciones unitarias del mundo, del hombre y de la historia, y solicita darle vida a las pequeñas historias e interpretaciones discontinuas, cuya suma de elementos cotidianos puede lograr estructuras complejas que no requieren de un hilo unificador que las limite a lo superficial y a lo liviano.

Como impulsores del Posmodernismo se reconocen a Lyotard, Vattimo, Benjamin y Rorty. Según Rojas (2001), las siguientes son las tesis en las que se basa el Posmodernismo y donde se muestra que el concepto metarrelato es esencial para este momento:

1. La calificación como metarrelato del pensamiento típicamente moderno y especialmente del pensamiento ilustrado.

2. Afirmación del fin de los metarrelatos.

3. La tesis del fin de la historia.

4. El Carácter lingüístico de la totalidad del saber humano.

5. El carácter fragmentario del lenguaje.

6. El fin de los metarrelatos traería como consecuencia el ocaso de una visión política global y revolucionaria.

7. El defender un liberalismo individualista.

8. La idea y práctica de una política localista.

Según la definición dada por Stephen (1998) dentro del contexto de la teoría crítica y el Posmodernismo, una metanarrativa es un esquema de cultura narrativa totalizador que organiza y explica conocimientos y experiencias. Es decir, hablar de metarrelato significa involucrar metarrelatos particulares dentro de un solo relato, para mirar el mundo y la esencia de los objetos que lo componen desde posiciones diversas en un contexto indivisible, ofreciendo sorprendentes soluciones a los interminables problemas humanos. A su vez, Diéguez (2004: 3) expone que un metarrelato es una gran narración con pretensiones justificatorias y explicativas de ciertas instituciones o creencias compartidas.

Jean-François Lyotard, filósofo e iniciador del Posmodernismo, utiliza el término relato en su ensayo ¿Qué es lo postmoderno? (1992) donde argumenta que la Modernidad ha intentado producir lo que podríamos llamar 'gran relato', ya sea el de la emancipación, a partir de la Revolución Francesa, o el discurso del pensamiento alemán sobre la realización de la razón." Es decir, para este autor un relato también puede ser cualquier discurso ideológico. En un trabajo posterior, La Posmodernidad (explicada a los niños), Lyotard habla de grandes relatos y de metarrelatos como términos sinónimos:

Cuando la enfoqué, en 1979, en torno de la cuestión de los "grandes relatos", mi intención era simplificarla, pero me temo que fui más allá de lo necesario. Los 'metarrelatos' a que se refiere la condición posmoderna son aquellos que han marcado la Modernidad: emancipación progresiva de la razón y de la libertad, emancipación progresiva o catastrófica del trabajo (fuente de valor alienado en el capitalismo), enriquecimiento de toda la humanidad a través del progreso de la tecnociencia capitalista, e incluso, si se cuenta al cristianismo dentro de la Modernidad (opuesto, por lo tanto, al clasicismo antiguo), salvación de las creaturas por medio de la conversión de las almas vía el relato crístico del amor mártir. (1996: 29) 
En La condición postmoderna, Lyotard (1993) inició la polémica en torno a la Posmodernidad, afirmando la afectación que han sufrido las reglas que rigen el juego de la ciencia, de la literatura y de las artes a partir del siglo XIX, obligando a dar un giro a los grandes relatos históricos propios de la Modernidad, caracterizada por su imperio de la razón y sus discursos ideológicos y científicos, anclados en disertaciones sobre la verdad y la justicia, cuyo propósito era legitimar las instituciones, las prácticas sociales y políticas, y las legislaciones. Afirma igualmente, que el eje de la Modernidad es el metadiscurso, caracterizado por su recurrencia a relatos tales como la dialéctica del espíritu, la hermenéutica del sentido, la emancipación del sujeto razonante o trabajador. Es entonces cuando propone un cambio frente a la que denomina la crisis de los relatos, concibiendo que de esta forma también se pronuncia por el fin del sentido emancipador de la historia. ${ }^{14}$

Desde un enfoque crítico, Lyotard (1993), se refiere a la necesidad de encontrar una forma para narrar una historia, que sea diferente a la que indistintamente denomina metarrelato o metanarrativa, al entender que ésta está compuesta por discursos que abarcan múltiples perspectivas y cuyo resultado es totalizante. Las narrativas dirigidas hacia un único fin, deben ser sustituidas por narrativas múltiples de historias, debido a que no poseen un único criterio de legitimación. Por ello, por Posmodernidad, entiende la extinción de los metarrelatos, en tanto proyectos universalistas tendientes a la emancipación de los seres humanos a través de la relación del conocimiento con la acción. Para Lyotard, la Posmodernidad es una apuesta por una ilusión de felicidad y la mejor opción para que el hombre se libere de la hegemonía de la Modernidad.

A su vez, Walter Benjamin en Tesis sobre la filosofía de la historia (1982) afirma que el concepto de historia como discurso unitario es una representación del pasado construida por los grupos dominantes, los que sólo permiten transmitir lo que ellos conciben como relevante, como lo demuestra la historiografía tradicional, dedicada a historiar batallas, revoluciones y tratados. Pero, en el momento en el que aparecen narrativas diversas, necesariamente se rompe la idea de que la historia tenga un devenir unitario; es decir, no existe una historia única sino muchas historias, así como tampoco un solo punto de vista cuando se narra una misma historia.

El mundo, dice Rorty (1989), no es un conjunto de elementos aislados y por ello exige ser visto desde un paradigma sistémico en el que se acepte la diversidad con todas sus consecuencias con el fin de trabajar conjunta y pluralmente, y no como lo pretendía el Modernismo desde un pensamiento unipolar y homogéneo, al no permitir la diversidad de discursos y formas narrativas. Hoy las narrativas deben facilitar el reconocimiento de una multiplicidad de lenguajes, cuyo ensamble puede darse a partir de los juegos que los representan desde la percepción de los distintos sistemas existentes en una realidad que en sí misma es flexible y transversal.

14 Para Lyotard (1993) el fin de la historia significa abolir el historialismo, a través de la comprensión de las calamidades humanas, dándoles un sentido que revele su necesidad emancipadora. De ahí que los que denomina grandes relatos, según él, hayan perdido su legitimidad y credibilidad histórica, convirtiéndose en expresiones de la violencia ideológica existente. 
En contra de las anteriores posturas, el italiano Gianni Vattimo (1990: 74) asegura que la Modernidad es una época que da un gran valor a lo novedoso y a lo original, desde un centro alrededor del cual giran, de una manera organizada, los acontecimientos humanos, donde la historia puede ser vista como un proceso unificado y, el no hacerlo, dificulta apreciar la idea de que sólo existe una realidad. Realidad, para nosotros, es más bien el resultado del entrecruzarse, del 'contaminarse' (en el sentido latino) de las múltiples imágenes, interpretaciones y reconstrucciones que compiten entre sí, o que, de cualquier manera, sin coordinación 'central' alguna, distribuyen los media. (Vattimo, 1990: 81). Así, continúa Vattimo, con la llegada de la Posmodernidad, aparece el afán por mostrar un mundo fragmentado, donde la influencia de la Sociedad de la Comunicación es determinante para hacer que ese mundo se vuelva caótico y confuso al deshacer las centralidades y permitir que cualquier cultura o subcultura se convierta en protagonista de la historia: A pesar de todos los esfuerzos de los monopolios y de las grandes centrales capitalistas, ha sido más bien que, radio, televisión, prensa han venido a ser elementos de una explosión y multiplicación general de 'Weltanschauungen'15 de concepciones del mundo (Vattimo, 1992: 14).

De acuerdo con lo antes expuesto, las narrativas anteriores a la Posmodernidad muestran la necesidad de comprender un solo estado sobre diversas dimensiones, para dar una respuesta panorámica conducente a construir una única realidad. Es decir, buscan representar un estado de cosas como si fuera una y sólo una cosa, recomponiendo hechos, materiales y superficies diversos, heterogéneos y caprichosos, asemejándose a esas bolas de cristal fragmentado que, colgadas del techo, en eterno movimiento, reflejan, resquebrajando, la realidad que los circunda. (Téllez, 1991: 190).

En un trabajo titulado Teoría de sistemas complejos, Madrigal (2004) explica que la realidad debe entenderse como un proceso dinámico tanto en la dimensión temporal como en la espacial y, cualquier sujeto que pretenda conocer la realidad tendrá que conformarse con irla conociendo poco a poco y la vida no le alcanzará para entenderla cabalmente en su totalidad. Por tanto, para irla entendiendo poco a poco, tendrá que ir haciendo "recortes" de la misma.

\section{LAS NARRATIVAS HIPERTEXTUALES}

\section{OBERTURA: Preludio narrado desde la Inteligencia Sintiente}

Cuenta una antigua leyenda china que hace mucho tiempo existían dos mundos donde habitaban seres muy diferentes, pero esta no era razón para que vivieran separados. Uno era el mundo de los espejos y el otro el de los humanos. Además de haber construido entre ambos un mundo armónico, todos tenían la posibilidad de viajar a través de los espejos. Un día, los seres especulares invadieron el mundo humano y sólo pudieron ser derrotados por las artes mágicas del Emperador de la China, quien conjuró un hechizo que los obligó a copiar mecánicamente los actos y las apariencias de los hombres. (Briggs y Peat, 2001: 13)

15 El término Weltanschauungen puede traducirse como "filosofia de la vida". 
En Alicia en el país de las maravillas, ${ }^{16}$ Lewis Carroll (1983) muestra un mundo extraño, pintoresco, incoherente, inquietante, absurdo y sistemático, en el que aunque se niegue la realidad, todo es posible. A través de extravagancias en los juegos de palabras, disparates sin sentido (nonsense), incoherencias irracionales, interrogantes no resueltos con sus miedos y ansiedades, situaciones y episodios absurdos e inverosímiles como detener el tiempo o cambiar el tamaño del cuerpo de Alicia o viajar a través de espejos que conforman redes, el autor representa el final del siglo XIX, narrando y describiendo de una forma visionaria, un mundo sin fronteras ni lógicas, donde reina lo inadmisible, vivenciado por seres representados en arquetipos humanos que por no comunicarse, conviven singularmente.

Una leyenda oriental y un cuento inglés sirven aquí para mostrar dos relatos donde aparecen la realidad como caos, representada como una red de signos y símbolos que cuestionan la percepción racionalista del mundo en el que sólo se alcanza el orden gracias al lenguaje y donde el inventario de lo real se logra desde su riqueza intertextual. Es decir, lo real puede ser representado por el lenguaje, convirtiéndose en el encargado de consolidar muchos de los momentos y motivos que la historia totalizante abandona. Concluida esta obertura sintiente, que sirva entonces la estructura musical para presentar los aportes a este artículo.

\section{PRIMER MOVIMIENTO: caracterización de las narrativas digitales}

La narrativa digital es un objeto virtual que dinamiza dos dimensiones: una técnica, desarrollada a través de un modelo, donde se engloban pequeños relatos que, sumados conforman un esquema abarcador, trascendente y universal, en el que además del lenguaje articulado oral o escrito, se utilizan diversos recursos audiovisuales con la ayuda de las nuevas tecnologías de la información y la comunicación. La otra dimensión es de carácter estético, donde se presenta el resultado de cada relato específico y su posibilidad de entretejerlo sistémicamente con otros, conformando el sentido y el significado de la representación de mundos a partir de las relaciones existentes entre ellos, logrando construir un gran relato en el que se precisen los desarrollos particulares relacionando objetos, actores, propiedades, características o hechos, etc.

Como características generales de las narrativas hipertextuales se pueden considerar:

- La función central de la narrativa hipertextual es la necesidad de constituir sistemas de representación, explicación y análisis a través de una compleja red de relaciones perceptivas.

- El tejido del lenguaje narrativo es más espacial que temporal por estar compuesto de fragmentos discontinuos y marcos no lineales. Esta lógica invita al lector a que haga valer su Inteligencia Sintiente, participando en el juego de la combinación de relaciones. En palabras de Gadamer (1977: 151) El juego se limita realmente a representarse. Su modo de ser es, pues, la autorrepresentación. Es decir, no hay una ruptura entre sujeto y objeto. La lectura se convierte en juego, hay jugadores, no espectadores-lectores.

$\overline{16}$ Lewis Carroll es el seudónimo utilizado por el escritor inglés Charles Lutwidge Dogson. 
- La narrativa intertextual, posibilita la recontextualización de los diversos elementos tomados a manera de fragmentos, convirtiéndose en medio para moldear narrativas elaboradas con antelación y conformadas por múltiples fragmentos desde las que se construyen metatextos.

- El tradicionalmente llamado narrador, pasa a ser ahora un organizador capaz de compilar las narrativas; es preciso advertir que no puede confundirse con un recolector ingenuo de textos preexistentes; es un productor activo de discursos para intertextualizarlos. Su función es similar a la del vitralista, artífice capaz de confrontar las multiplicidades para representar una realidad en una sola imagen.

- Se da prelación a la expresión mediante imágenes, las que cumplen una función tanto narrativa como descriptiva.

- La palabra tiene una función explicativa y adquiere un rol significativo en la medida en que se integre a una sintaxis de estímulos determinada por la articulación de imágenes, sonido (grabación de voces: oralidad) y pequeños textos. Así se otorga la ilusión al lector de poder traspasar los signos, sin necesidad de mediaciones. (Bolter, 1998).

- La textualidad digital une las lexías ${ }^{17}$ a través de vínculos electrónicos que pueden adoptar la forma de palabras, imágenes, sonido, vídeo, etc. (Landow, 1995).

- Las producciones de la narrativa hipertextual integran el proceso creativo con el proceso receptivo en un mismo espacio de representación, participación y juego.

- Los materiales narrativos son una especie de indicadores que contribuyen a otorgar significados, para que el lector los asuma y proponga su visión sintiente. Es decir, el lector es también productor del texto, cuando entiende que narrar es crear mundos de vida haciendo uso de la memoria, alimentadora de su capacidad discursiva.

- Es necesario cuestionar la validez de las formas clásicas de recepción, reconociendo a la experiencia comunicativa como el complemento necesario del proceso creativo y, consecuentemente, apuntar hacia la percepción fragmentada de la narrativa, convirtiéndola en motivo de exploración con miras a representar sin restricciones, aquello que se desea expresar.

- Se permite alternar la analepsis y la prolepsis. Según Genette (1989) éstas consisten en un mecanismo que faculta al narrador efectuar dos movimientos narrativos en el tiempo, mirando indistintamente hacia atrás (analepsis) o hacia delante (prolepsis).

- La hipernarrativa otorga al ser humano su capacidad creativa, al facultarlo para producir objetos que soportan, vinculan y direccionan información añadida. ${ }^{18}$

- La dimensión tecnológica se convierte en valor cuando se utiliza para establecer comunicaciones participativas. (Castoriadis, 2002)

- Genera un alejamiento de la eterna búsqueda por hallar la verdad, al reutilizar el material descriptivo para resquebrajar su uso convencional y abrir su significado a otras referencias menos habituales, procedimiento metafórico que conduce a la virtualidad del mundo y sus múltiples realidades.

17 Se denomina lexía a la unidad léxica compuesta de morfemas relacionados por un alto índice de inseparabilidad.

$18 \mathrm{Al}$ acto de crear lo define Lussato (1982) como la capacidad de producir información añadida; es decir, todo objeto que posee información es un producto del acto creativo. 


\section{SEGUNDO MOVIMIENTO: rol de los investigadores-autores en las narrativas digitales}

A la hora de crear un hipertexto, el investigador-autor se verá sometido a gestionar conocimiento así como al aprovechamiento expresivo de las facilidades hipertextuales, además de la tensión que implica esta nueva narratividad perceptual. Dentro de las cualidades que de un investigador-autor de narrativas digitales tenemos, bien vale la pena subrayar:

- En un hipertexto basado en narrativas, el papel del investigador consiste en narrar y describir el mundo, los seres que vivieron o aún viven en él, identificar las propiedades y características que le otorgan una identidad, para finalmente proyectar ese cosmos y esos actores a manera de representación, a través del lenguaje más apropiado para lograrlo.

- El investigador es un oyente de proposiciones y un observador de realidades que cuenta los hechos que han sucedido en un espacio y en un tiempo definidos, además de identificar a quienes han servido como protagonistas de esos sucesos. De esta forma construye mundos coherentes.

- Quien desarrolla una investigación, detecta y asume consecuentemente todos los retos y las alternativas que ofrecen los alientos creativos de las culturas, con la obligación de actuar con ellas, para ampliar la significación que en sí mismas poseen, más allá de lo exclusivamente instrumental o tecnológico.

- Si en la investigación se usan las estrategias apropiadas y se desarrollan aquellas competencias que apuntan a cambiar las prácticas discursivas, que desde las narrativas no sólo presenten, sino también representen a la sociedad imbuida en una realidad en formación y comprometida con la urgencia de lo cotidiano, podrá apreciarse que el concepto que hoy se tiene de ser humano es más un evento que una estructura, debido a que no es un ser pensante que siente sino un ser sintiente (emocional) que piensa.

- Se requiere proponer proyectos basados en esquemas de representación e imaginación, a partir de los cuales se establezcan conexiones, diálogos, dialécticas, multiplicidades y simultaneidades, donde sea la hermenéutica del texto, representada en la escritura, quien guíe la correspondencia entre el pensar y el vivir.

- Un investigador podrá anticiparse a los hechos del mundo desde un horizonte de sentido, leyendo e interpretando los signos que conforman las nuevas representaciones de la realidad, alimentando su percepción de las singularidades y haciendo ver que lo particular también cumple una función reveladora que, sólo en algunas ocasiones puede hacerse extensiva.

- Es importante que el investigador evite la homogeneidad y los determinismos para comprender que la escritura es un modelo del mundo y la representación de su realidad, donde lo real está más allá de los textos y de las escrituras, aunque sólo sea accesible a través de estos dos medios.

- Se espera que los textos sean construidos a varias manos y haciendo uso de la inteligencia colectiva. No hay que olvidar que los lectores ya no son receptores pasivos ni indiferentes, sino participantes que inteligentemente sienten el acto de representación creativa. 
- Se espera que la investigación presente un enfoque interdisciplinar, en el cual cada investigador aporte su formación disciplinar, para definir desde un comienzo un marco epistémico común, surgido de los propósitos del estudio, pues...

(...) si no se tienen objetivos comunes, el resultado será una investigación multidisciplinaria donde cada disciplina aportará su propia visión del asunto investigado (...) no es necesario que homogeneicemos nuestros conocimientos sino nuestra investigación, con base en objetivos comunes que surgen a partir de una pregunta rectora que servirá para orientarla. (Madrigal, 2004).

- Quien investiga debe distinguirse por ser reflexivo para hallar el sentido del significado de la narrativa. Esto se logra a través de la autoidentificación, la cual en este caso es el modo de escritura diferenciado por la búsqueda de su propia identidad. (Culler, 1984: 161).

\section{TERCER MOVIMIENTO: Narrar utilizando el "Sistema de Marcos"}

Actualmente, la Inteligencia Artificial explica la posibilidad de narrar utilizando marcos como sistemas de acción que permiten, a manera de artefacto escritural, dar cuenta de las experiencias y vivencias humanas, adquiriendo forma de historia, o mejor, de una historia que cuenta varias historias que se deben adaptar a lo que Greimas (1973) denomina el modelo actancial, retomándolo de las propuestas de Propp $(1981)^{19}$ y Souriau, ${ }^{20}$ con la idea de conformar una estructura narrativa sobre la cual sea posible representar todo un proceso semiótico.

Minsky (1975), creador del sistema de marcos, lo define así:

Esta es la esencia de la teoría de los marcos: cuando nos enfrentamos a una nueva situación, o cuando realizamos un cambio sustancial en nuestra visión de un problema, seleccionamos en nuestra memoria una estructura denominada marco. Este es un esquema que nosotros recordamos y que debemos adaptar a la realidad cambiando los detalles según sea necesario.

El sistema de marcos se entiende como una forma de textualidad digital en la que los vínculos electrónicos unen fragmentos de textos que pueden adoptar la forma de palabras, imágenes, sonidos, vídeos, etc., lo que de suyo conlleva la realización de una lectura diferente, a la que bien podría denominarse multilineal, multisecuencial o no lineal. Es este sistema el que permite que lo que antes se consideraba como función exclusiva de un narrador, también pueda ser adoptada por los lectores desde su Inteligencia Sintiente, como coautores y copartícipes del texto narrativo, debido a que tienen la posibilidad de hacer sus propias relaciones, realizar sus propios enlaces y ampliar, de acuerdo con su interés, el campo contextual del hipertexto.

Este modelo es reconocido como una forma de representación del conocimiento del mundo, pues permite realizar actos cognitivos fundamentales como percepciones, comprensión lingüística y acciones (Van Dick, 1976: 31). Como método utilizado por el pensamiento

19 Vladimir Propp en su estudio de los cuentos maravillosos o de hadas, afirma que todos ellos siguen una misma estructura, compuesta básicamente por 31 funciones o acciones realizadas por un personaje.

20 Eienne Souriau dedica su estudio a las situaciones que se presentan en una obra de teatro desde seis funciones básicas, cuyas combinaciones conducirán a unos resultados infinitos y diversos. 
complejo, ${ }^{21}$ la mente tiene la capacidad de interpretar nuevas situaciones a través del reconocimiento y potenciación de estructuras de datos, representando una situación estereotipada que se almacena y contextualiza previamente, teniendo en cuenta sus elementos más significativos. Se asume que es gracias a los marcos que se conforman nodos y relaciones con el fin de generar el sistema, además se dinamizar los horizontes de las experiencias escritoras y lectoras hipertextuales.

Eco (2000: 115-116) describe un marco como un texto virtual o una historia condensada (...) [donde se corre el riesgo de trabajar desde] hipótesis textuales destinadas al fracaso. Por ello, puede desarrollarse, en términos de Kristeva (1974) una competencia hipertextual, a la que dicha autora entiende como una periferia extrema de una enciclopedia, capaz de abarcar todos los sistemas semióticos y las ontologías con los que se encuentra familiarizado el lector. Para trabajar con este sistema se hace necesario, dice Eco (2000), establecer jerarquías narrativas comunes entre los marcos que componen su conjunto; en el gráfico siguiente se representa la propuesta de este autor:

Gráfico 1. Jerarquías narrativas contextualización de Eco (2000: 117-118)

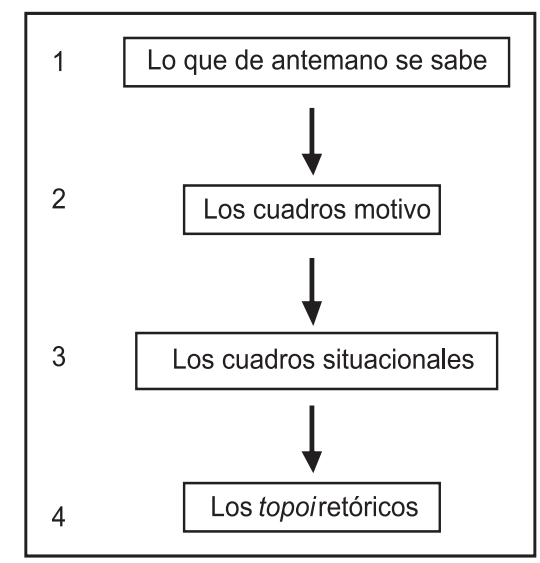

De estos cuadros comunes, se despliegan subdivisiones que a su vez van formando los esquemas narrativos particulares de cada temática que se desarrolla, con el fin de lograr un repertorio seleccionado y restringido de los conocimientos que se desea compartir. Esta estructura permite no sólo desarrollar la competencia hipertextual sino también una aproximación a los sistemas ideológicos de quienes los construyen $\mathrm{y}$, al mismo tiempo, conformar el sistema ideológico personal del lector, al permitirle la libertad de navegar de acuerdo con sus emociones y sus intereses. (Eco, 2000: 120).

21 La complejidad, en términos de Lewis (2001: 2), es la ciencia que se ocupa de los sistemas complejos adaptativos; la ciencia que estudia los sistemas dinámicos no lineales; los sistemas dinámicos con sensibilidad a las condiciones iniciales. Es decir, el pensamiento complejo es fundamentalmente una respuesta, un ver diferente, un volver a plantearse la construcción del conocimiento, ya no desde la simplicidad, sino desde nuevas visiones, con el fin de comprender los fenómenos de la realidad. 


\section{CUARTO MOVIMIENTO: el transcurrir metodológico}

Desde lo metodológico, las hipernarrativas se comprometen con procesos que se desprendan de lo que podría denominarse una ontología de la actualidad, por ser la representación del pensamiento centrada en una actitud frente al mundo, la naturaleza, la vida y el conocimiento. Trabajar en narrativas digitales significa contar con un pensamiento relacional centrado en el sujeto cognoscente que pretende una interpretación del mundo y de la vida; es decir, es metodología en tanto manera de hacer pero eso sí, teniendo siempre en mente el sentido de lo interdisciplinar. Al respecto, la propuesta de Ciurana (2001: 11) está encaminada a superar las debilidades del pensamiento positivista, así como a pensar de forma dialógica, que no es otra cosa que hacer dialogar en un mismo espacio intelectual lo complementario, lo concurrente y lo antagonista. Es intercomunicar lógicas diferentes a la hora de explicar fenómenos complejos.

El método posibilita la acción investigativa, al efectuar la interacción de las disciplinas con el fin de lograr el conocimiento de la realidad, a partir de la práctica, la reticulación y el pensar articulado; en términos utilizados por complejidad, es ese ir y venir del todo a la parte y de la parte al todo. Sólo así el investigador podrá imaginar y crear mediante la práctica de los macroconceptos que identifican cada narrativa.

De otro lado, el método coevoluciona con lo real empírico. Si la pretensión metodológica es mantener una relación con la realidad, el método tendrá que facilitar el aprendizaje y el aprehendizaje, por ser al mismo tiempo programa y estrategia de conocimiento. Por todo esto, nunca es tajante ni dictatorial, pues una relación con el mundo jamás puede eliminar el margen de incertidumbre. Expresado lo anterior en palabras de Ciurana (2001: 5) es la lógica de la sociedad no es la lógica del sistema funcionalista, es la lógica del sistemaorganización. No es desde arriba desde donde se determinan las posiciones del sujeto. Esa es una de las raices del conflicto social.

Como estrategia metodológica, el sistema de marcos busca no sólo explicar, sino también comprender. No sólo distinguir y analizar sino también articular a través de la organización. No se trata dar explicaciones lineales sino de tener un sentido de la multidimensionalidad y de la recursividad, de poseer un sentido de la lógica y de la dialógica. Es por eso que entre los principios planteados por Morin, la dialógica, lo hologramático y la recursividad, son las estrategias fundamentales de la nueva racionalidad. Se trata de un modelo actitudinal que tiene en cuenta tanto el conocimiento como la acción.

La herramienta esencial para las narrativas hipertextuales es la razón, si se entiende que es a través de ella como se llega a los instrumentos que permiten conocer el universo como algo completo, instrumentos que son, evidentemente, de naturaleza racional. Claro está que aquí sería mejor hablar de racionalización, en cuanto a que es ésta la que permite el juego y el diálogo entre el espíritu creador y las estructuras lógicas. De esta combinación, juego, diálogo y estructura, surgen los elementos que conforman las herramientas y que en últimas se derivan de tres de los principios fundamentales que le pertenecen al pensamiento complejo. 
Recurriendo nuevamente a Morín (2001), éstos son:

- El principio dialógico, que consiste en la cooperación entre lo ordenado y lo que está en desorden. Orden y desorden son dos enemigos: uno suprime al otro pero, al mismo tiempo, en ciertos casos, colaboran y producen la organización y la complejidad. El principio dialógico nos permite mantener la dualidad en el seno de la unidad. (p.10)

- El principio de recursividad organizacional, el cual se refiere a que los procesos tienen la capacidad de ser al mismo tiempo producto y producción. Morin explica este término a través del ejemplo del remolino: Cada momento del remolino es producido y al mismo tiempo, productor. Un proceso recursivo es aquél en el cual, los productos y los efectos son, al mismo tiempo, causa y productores de aquello que los produce. (p. 106).

- El principio hologramático, hace referencia a la relación que existe entre la parte y el todo. Morin traza un símil con un holograma físico: el menor punto de la imagen del holograma contiene la casi totalidad de la información del objeto representado. No solamente la parte está en el todo, sino que el todo es la parte. (p. 107).

Teniendo en cuenta estos principios, dice Maldonado (2001) que el trabajo desde la complejidad, exige la utilización de herramientas conceptuales, debido a que es ante todo una teoría de las probabilidades; es decir, se permite no mirar al mundo como algo fijo, estable, jerárquico o periódico, sino como un mundo de sorpresas, dinámico, imprevisible, interconectado e irreversible, y además, lo hace desde el mecanismo de la abstracción, el que conceptualmente explica al mundo como algo que es en sí mismo complejo.

Una herramienta indispensable es la observación, pues es ésta la que permite elaborar una descripción lógica y conciente del mundo. Es precisamente en este proceso de observación, donde nace el concepto de autoorganización, que no es otra cosa que la actividad selectora y ejecutora de las interacciones que pueden ser descritas; es decir, el mundo elegido como objeto/sujeto de la narrativa. Es a través de la observación como se generan las descripciones de la realidad que, aunque muchas veces son provisionales, aseguran el curso de los procesos que se desea estudiar. Toda narrativa exige el ejercicio descriptivo y por ello es necesario utilizar métodos de inferencia que sean rigurosos, sistemáticos y que estén de acuerdo con el aspecto estudiado. Si la tarea consiste en comprender el mundo observado, necesariamente ésta contiene tres ingredientes: representación, información e inferencia.

De esta forma, se puede decir que lenguaje y mundo son inseparables y ambos forman un tejido de relaciones sin puntos de referencia fijos. Si se define la narrativa digital como un sistema simbólico de comunicación, fundamentado en una relación convencional entre significantes, significados, imaginarios, representaciones mentales y relaciones lógicas entre dichas representaciones, no se puede decir que el lenguaje sea exclusivo de la lingüística y es necesario admitir la existencia de diversas formas de lenguaje, como el plástico, el arquitectónico, el de patrones, el musical, el del sonido y el ruido, así como la imagen, el olfato, las cosas, las expresiones, las emociones, las construcciones, los espacios, los lugares, en fin, todo aquello que tiene en sí mismo un significado comunicable desde un sistema de signos. Como término polisémico, el lenguaje, es el que permite percibir y comprender mensajes, es el que autoriza 
que alguien reciba sentidos y significados a partir de convenciones establecidas y reaccione frente y desde unos cánones comunicativos.

El sistema de marcos puede ser verbal o no verbal, pero siempre debe ser transmisible para lograr establecer algún tipo de comunicación. Como herramienta totalizante el lenguaje expresa todo aquello que el ser humano está en capacidad de sentir, hacer y configurar como representativo y se constituye en el medio a través del cual se funden hombre y mundo, debido a que es la representación de su pertenencia; quien posee un lenguaje tiene al mismo tiempo un mundo contenido en él y sólo hay mundo donde hay lenguaje. En este orden de ideas, se puede afirmar que lenguaje, comprensión y experiencia del mundo mantienen una estrecha relación, y es en el lenguaje donde se revela la significación del mundo. Tal vez es por ello que Gadamer (1977) afirma que el lenguaje es el que permite que los hombres comprendan el mundo, o mejor, es el que se encarga de que los seres aprehendan la existencia del mundo.

Finalmente, como herramienta tecnológica muchos autores destacan el papel del lenguaje de los computadores como decisivo para el estudio de la complejidad, debido a que él proporciona un mundo experimental que permite representar, calcular, visualizar, manipular, observar y describir los comportamientos humanos y no humanos de una manera cualitativa. El computador es además una herramienta conceptual que enseña la simulación de la realidad, y a través de él se pueden establecer relaciones que se complementan, entre la inteligencia sintiente y la inteligencia artificial. (Maldonado, 2001).

\section{FINAL: conclusiones y recomendaciones}

Dice Eco (1996: 96) que pasear por un mundo narrativo tiene la misma función que desempeña un juego para un niño. En este paseo, que puede realizarse tanto desde el rol de autor o como de lector, cada narrativa contada significa jugar a dar sentido a algo que ocurrió, ocurre u ocurrirá en la realidad. Según este autor, la narrativa cumple una función social, además de ser una explicación válida sobre por qué el ser humano es un eterno contador de historias.

Hasta hoy, las diversas disciplinas se han venido moviendo en su propio campo, el que habían considerado como exclusivo. Lo que las narrativas hipertextuales pretenden es moverse por varios campos de conocimientos, en forma de redes o relaciones. No se puede negar que el método científico haya cumplido un papel preponderante dentro de los avances de la ciencia, pero su misma forma rígida fabrica una barrera de separación entre el sujeto que investiga y el objeto investigado. Desde luego, en las ciencias formales el paradigma positivista no sólo es válido sino también necesario, pero cuando el objeto de conocimiento es al mismo tiempo un sujeto, su condición humana no puede permitirle someterse a mecanicismos, determinismos o matematizaciones.

Aunque muchas narrativas de la Posmodernidad dan una cierta centralidad a la ciencia y la tecnología, aún se reclama autenticidad y legitimidad estética a través de la búsqueda de esquemas creativos y de nuevos métodos y conceptos de creación, al entender que toda forma 
se expresa por sí misma, logrando con ello relativizar el carácter aparentemente central del discurso científico.

Traducido lo anterior al lenguaje utilizado por la Inteligencia Sintiente, lo que se desea es confirmar que para elegir lo que se va a narrar, es necesario preferir $\mathrm{y}$, esa preferencia por lo general está supeditada a dos condiciones: La primera se basa en reconocer que el sentir humano es intelectivo; la segunda, se centra en aceptar que para aprehender la realidad debe hacérselo desde una intelección sintiente. Sólo así es viable apreciar que la realidad se actualiza en la aprehensión verdadera y se convierte en fuente confiable de posibilidades para su propia realización y representación.

Las narrativas digitales, en tanto concepto contemporáneo, lo que pretenden es abordar el problema del entorno humano y las relaciones que en ese entorno existen; investigar desde una mirada más amplia e interdisciplinar, integrando desde distintas visiones la manera como cada una de ellas acostumbra trabajar. Su pretensión es asumir una mirada relacional, al estar implicando a un objeto/sujeto complejo en todo el sentido del término y planteando que su estudio y comprensión, se lleva a cabo desde una mirada compleja.

Como recomendaciones, se sugiere tener en cuenta que:

- La experiencia de componer hipertextos narrativos no es el fin de la historia, sino el descubrimiento de múltiples historias.

- Debido a que hoy, la velocidad de la información deja poco tiempo para la reflexión, la narrativa puede ser asumida por las nuevas tecnologías digitales, mientras sean entendidas como un presente continuo, simultáneo, instantáneo e inmediato, como lo es una imagen electrónica.

- Todo hipertexto podrá ser apreciado como herramienta de expresión que utiliza múltiples lenguajes acompañados de la tecnología, además de la disposición de un nosotros creador, con el fin de ponerla en función de su necesidad expresiva.

- Las narrativas digitales pueden fácilmente convertirse en mapas cognitivos, en fractales, en segmentos y yuxtaposiciones, lo que contribuye a que se puedan ofrecer múltiples combinaciones de estilos.

- La estética valorada desde esta forma narrativa, emerge de una ideología capaz de incorporar la tecnología y el arte, obteniendo con ello un producto heterogéneo y fragmentado dentro de su universalidad.

- Se hace necesario recuperar la memoria de los vencidos y los olvidos de la historia para representar cualquier vida humana.

- La suma de realidades distintas, culturas múltiples, necesariamente tienen historias diferentes y, por supuesto, utopías disímiles. 


\section{REFERENCIAS BIBLIOGRÁFICAS}

ALPINI, A. Proliferación de las historias. En: http:/www.chasque.net/frontpage/relacion/9808/ fin_historia.htm.

BARTHES, ROLAND (1966). Introducción al análisis estructural del relato. En: Niccolini, Silvia (comp.)(1977). El análisis estructural. Buenos Aires: Centro Editor de América Latina.

BENJAMÍN, W. (1982). "Tesis de filosofía de la historia." En: Discursos interrumpidos. Taurus: Madrid.

BOLTER, J.D. (1998). Ekphrasis, realidad virtual y el futuro de la escritura. En: NUNBERG, Georffrey. (Comp.) El futuro del libro. ¿Esto matará eso? Barcelona: Paidós.

BRIGGS, J. Y PEAT, F.D. (2001). Espejo y reflejo: del caos al orden. Guía ilustrada de la Teoría del Caos y la ciencia de la totalidad. Barcelona: Gedisa.

CALLINICOS, A. (1991). Against Postmodernism: A Marxist Critique. Cambridge: Polity Press.

CALVINO, I. (2001). Seis propuestas para el próximo milenio. Bogotá: Siruela.

CÁRCAMO BERRÍO, O. (2007) “El concepto de metarrelato en el postmodernismo”. En: revista Aulas y Maestros, Año1, No.1.

CARROLL, L. (1983) Alicia en el País de las Maravillas. Madrid: Edaf.

CASTORIADIS, C. (2002). La insignificancia y la imaginación. Trotta: Madrid.

CIURANA, E.R. (1999-2001) Complejidad. Elementos para una definición. Universidad del Salvador, Vicerrectorado de Investigación y Desarrollo, UNESCO.

CULLER, J. (1984). Sobre la deconstrucción. Madrid: Cátedra.

DIÉGUEZ, ANTONIO. (2006). La ciencia desde una perspectiva postmoderna: Entre la legitimidad política y la validez epistemológica. II Jornadas de Filosofía: Filosofía y política (Coín, Málaga 2004), Coín, Málaga: Procure, 2006, pp. 177-205. En: http:// webpersonal.uma.es/ DIEGUEZ/hipervpdf/CIENCIAPOSTMODERNA.pdf.

ECO, U. (1996) Seis paseos por los bosques narrativos. Barcelona: Lumen.

ECO, U. (2000). Lector in fabula. La cooperación interpretativa en el texto narrativo. Barcelona: Lumen.

GADAMER, H-G. (1977). Verdad y método. Sígueme, Salamanca, 
GARCÍA JIMÉNEZ, J. (1994). Narrativa audiovisual. Cátedra, Madrid.

GENETTE, G. (1989). Figuras III. Barcelona: Lumen.

GREIMAS A.J. (1973). En torno al sentido. Fragua: Madrid.

HABERMAS, J. (1981). "Modernity versus Postmodernity". New German Critique, No. 22, Special Issue on Modernism.

KRISTEVA, J. (1974) El texto de la novela. Barcelona: Lumen.

LANDAW, G.P. (1995) Hipertexto. La convergencia de la teoría crítica contemporánea y la tecnología. Barcelona: Paidós.

LUSSATO, B. (1982) El desafío informático. Presente y futuro de una explosión tecnológica. Barcelona: Planeta.

LYOTARD, J-F. (1992). ¿Qué es lo postmoderno? En: Revista Zona Erógena, No. 12.

LYOTARD, J-F. (1993) La condición postmoderna, Barcelona: Planeta-Agostini.

LYOTARD, J-F. (1996). La Posmodernidad (explicada a los niños). Barcelona, Gedisa.

MADRIGAL GONZÁLEZ, S.A. (2004) Teoría de sistemas complejos. En: http://www. laventanadekabbik.blogspot.com.

MAESTRO, JESÚS G. (1984). Introducción a la Teoría de la literatura. En: http:// mirabeleditorial.com/pdf/05520-20ITL620-20Novela.pdf.

MALDONADO, C. E. (ed.), y otros. (2001) "Visiones sobre la complejidad”. El Bosque, Colección Filosofía y ciencia, Vol.1, Bogotá.

MÁRQUEZ, A. (2003). Modernidad y Postmodernidad entre el humanismo histórico y la razón escéptica. Trujillo: Ágora, (11), 123-132.

MINSKY, M. (1975). A framework for Representing Knowledge, Winston. P. Ed. The Psychology of Computer Vision. Nueva York: MacGraw-Hill.

MORIN, E. (2001) Introducción al pensamiento complejo. Barcelona: Gedisa.

PARRA CONTRERAS, R. Y ALI, M. (2005). Conformación y crisis de la Modernidad. Julio de 2005, vol.10, no.30 En: <http://www.serbi.luz.edu.ve/scielo.php?script=sci arttext\&pid $=\mathrm{S} 1315-52162005007000009 \& \operatorname{lng}=\mathrm{es} \& \mathrm{nrm}=\mathrm{iso}>$. 
PROPP, V. (1981). Morfología del cuento. Fundamentos: Madrid.

ROBLEDO Z., E. La Nueva Era: una crítica anímica y materialista. En: http://www.geocities. com/elforonuevo/criticaanimica.htm.

RODRÍGUEZ, J.A. "Posmodernidad, literatura y otras hierbas". En: http://www.javeriana. edu.co/Facultades/C_Sociales/Facultad/sociales_virtual/cultura_comtemporanea/ publicaciones/Posmodernidad/Posmodernidad_fcs.html.

ROJAS OSORIO, C. (2001). Foucault y el posmodernismo. Heredia, C.R: Universidad Nacional, Puerto Rico.

RORTY, R. (1989). Contingencia, ironía y solidaridad. Barcelona: Paidós.

STEPHENS, J. (1998). Retelling Stories, Framing Culture: Traditional Story and Metanarratives in Children's Literature.

TÉLLEZ, F. (1991) “Los rostros de la escritura”. En: Palimpsestos. Bogotá: Centro editorial Universidad Nacional de Colombia.

VAN DICK, T. (1976). Macroestructuras y conocimiento. Carnegie Mellon University, Pittsburg.

VATTIMO, G. (1985). El fin de la modernidad, nihilismo y hermeneútica en la cultura posmoderna. Barcelona: 1985.

VATTIMO, G. (1990). La sociedad transparente. Barcelona: Paidós.

VATTIMO, G. (1992). "Posmodernidad: ¿Una sociedad transparente?". En: Vattimo, G., y otros, En torno a la Posmodernidad, Barcelona: Anthropos.

ZUBIRI, X. (1989) Inteligencia sentiente. En: Inteligencia y realidad. Madrid: Alianza Editorial - Sociedad de Estudios y Publicaciones. 